\title{
Design and development of the sea surface drifting buoy
}

\author{
Yonghua CHEN, Qingkui LIU, Jiangbo JIANG, Zuotao NI, Xiaolong LI \\ \{Yonghuachen@aliyun.com, Liuqk5102@163.com \} \\ Institute of Oceanology, Chinese Academy of Sciences, Qingdao 266071, China
}

\begin{abstract}
A sea surface drifting buoy system based on Beidou communication system is designed and developed by Institute of Oceanology, Chinese Academy of Sciences. It employs a low power consumption chip, STM32F103RCT6, as the core of the control system, which can collect and process the data of the ocean environment automatically and monitor the status of the buoy system. Then the marine data are transferred to the lab on shore in real time by Beidou satellite. With the power management function, this system will reduce system power consumption greatly and extend the working time of the buoy. By placing and using the buoy at sea, we verify the feasibility and reliability of this system, which has provided the reliability support of acquiring some realtime elements and track currents of the ocean current in some certain sea area in long time realtime access to the sea currents.
\end{abstract}

Keywords: Drifting buoy; Beidou communication system; Data acquisition; Real-time transmission; Power management.

\section{Introduction}

Surface drifting buoy is a kind of small ocean data buoy which is developed according to the needs of ocean investigation, environmental monitoring and scientific experiment[1]. It is the tool that belongs to the Lagrange method to measure the sea surface laminar and large area, ocean hydrological and meteorological observation. It depends on the fixed satellite communication network to locate and collect all kinds of parameters, which is processed by the ground receiving station. The utility model has the advantages of small size, low cost and convenient use. It can be used for large area investigation, air sea interaction, ocean circulation research, natural disasters and sudden environmental pollution survey, etc.[2]. With the development of satellite communication technology and the decrease of communication cost, more and more marine environment monitoring instruments use satellite communication to transmit data in real time. At present, the current mainstream satellite communication systems are Iridium system, Maritime satellite system, Argos system and the Beidou satellite system in the world.

Drifting buoy system designed in this paper is a kind of application for offshore sea surface environment observation, we adopt the method of delivery in a sea group to a wide range of monitoring the changes of ocean currents $[3,4]$. The use of standard temperature sensor body is equipped with timing acquisition of sea surface temperature along with the BDM910 and BD2 module with Beidou navigation positioning module B1/GPS L1 miniaturization collected by Beidou satellite positioning information is transmitted to the ground-based receiving station[5]. Domestic Beidou satellite communication is also conducive to data confidentiality. The drifting buoy system has been put into actual operation, the system is stable and the communication is good, which meets the requirements of real-time monitoring of offshore environment.

The project was financially supported by Key research and development of science and technology Program (Grant No 2016YFC1402602), by Science Fund for Technology Strategic Pilot of the Chinese Academy of Sciences (XDA1 1040306), by major scientific research equipment R \& D projects of Chinese Academy of Sciences (Grant No. YZ201522 and No. YZ201625). 


\section{System structure}

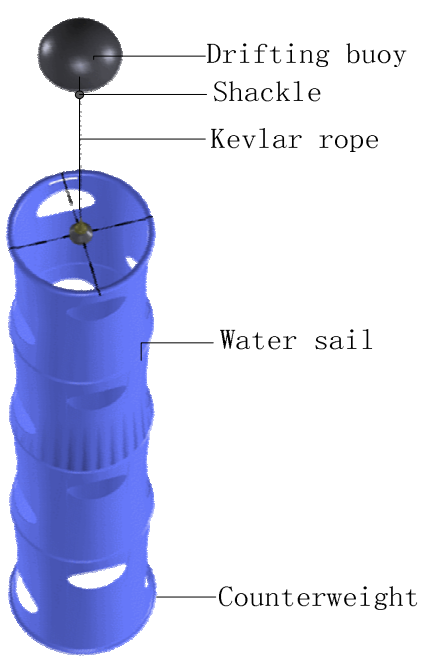

Fig. 1. Structure of drifting buoy

The sea surface drifting buoys are composed of buoy body, water sail, counterweight and connecting mechanism. The water sail drives the object to be consistent with a deep water layer. There are all kinds of sensors, control system, positioning system, communication system and battery packs. In order to guarantee the drifting buoy location, timing will process the collected data and send it to the station of data collection, which will get the tracking analysis on the regional ocean currents and provide the basis for regular maintenance of the subject. The data needed to be collected and processed as follows:

Table 1. data elements

\begin{tabular}{|l|l|l|}
\hline Collection elements & Measuring range & Accuracy \\
\hline Temperature & $-10^{\circ} \mathrm{C} \sim 40^{\circ} \mathrm{C}$ & $0.1^{\circ} \mathrm{C}$ \\
\hline Location & All position & $5 \mathrm{~m}$ \\
\hline Flow measurement & $\begin{array}{l}\text { Depends on the calculated value of } \\
\text { Lagrange }\end{array}$ & \\
\hline
\end{tabular}

The drifting buoy needs to collect the measured data and the status information of the satellite, including the battery voltage, water alarm and the sea temperature, with the Beidou short message way to upload satellite station. The drifting buoy is needed to transport for a period of time, so in order to avoid the waste of electricity in the process of transportation, the electromagnetic switch control system is put into operation in the standard body.

\section{The design of hardware system}

The drifting buoy system for a Quasi real-time tracking and acquisition of a regional ocean, the hardware circuit is composed of the main control chip, the temperature acquisition circuit, the satellite positioning and communication circuit, the voltage regulator circuit, the clock circuit and the switch detection circuit. The main control chip collects the sea surface temperature by the A/D acquisition circuit, gets the position by Beidou communication module BDM910 with the protocol of RS232 and 
uploads the information to the satellite station. The overall system block diagram is shown in Figure 2.

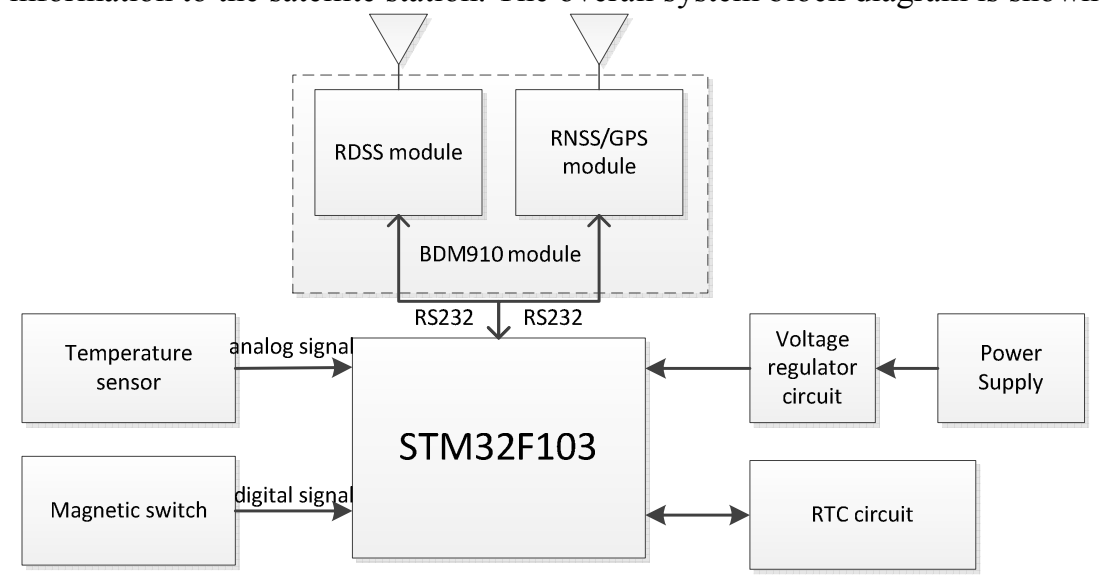

Fig. 2. System structure block diagram

\subsection{Main chip Introduction}

The main chip of the system selects the STM32 series microcontroller based on Cotex-M3 kernel, which is mainly pushed by ST Company, STM32F103RCT6 is an enhanced STM32 series chip, operating frequency $72 \mathrm{MHz}$, extended 2 I2C interface, 3 SPI interface, 5 USART interface and 1 SDIO interface. The on-chip also has 3 12-bits sampling rate of up to $1 \mathrm{MHz} \mathrm{ADC}$ and up to 11 16-bits timers. Combined with the design requirements of the system, the chip is selected as the main chip of the control system.

\subsection{Temperature acquisition module design}

We choose TI produced by ADS1115 as the temperature acquisition circuit of the AD conversion chip, with the internal reference voltage, high precision, low power consumption, the use of IIC communication. Due to the unique ADS1115 sigma delta conversion technology, the system can adapt to the noise environment, and it is suitable for the acquisition of wide dynamic range voltage and low frequency signals. Front-end acquisition as shown in Figure 3.

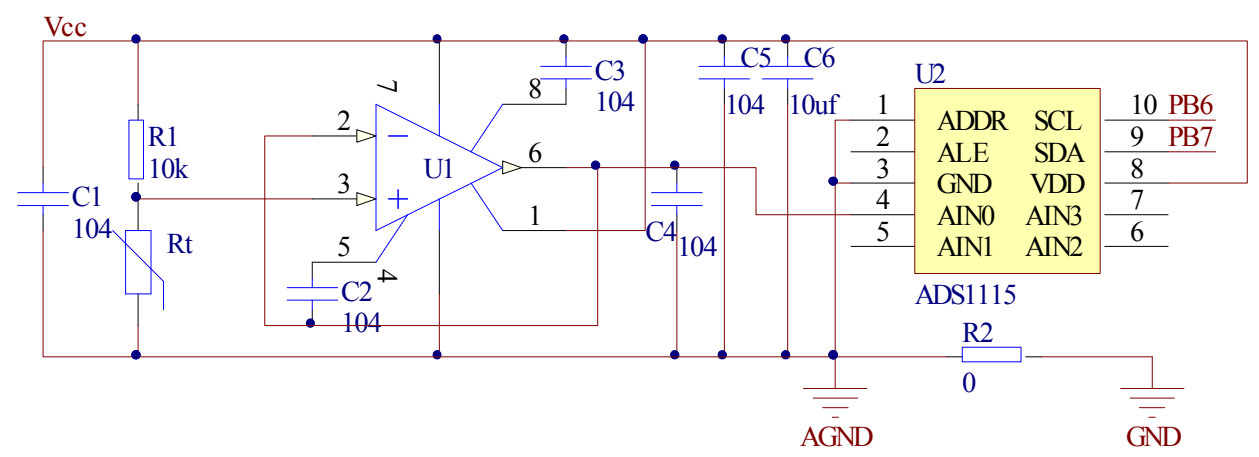

Fig. 3. A/D conversion module circuit diagram

In this paper, we use the resistance ratio method. Temperature probe using NTC thermistor,R1 selects the wafer resistance, the accuracy reaches $0.1 \%$,the temperature drift coefficient is only $15 \mathrm{ppm}$, and $\mathrm{U} 1$ plays the role of voltage follower in the acquisition circuit. As shown from Figure $3, \mathrm{~V}_{\mathrm{o}}=$ $V_{c c} \times R_{t} /\left(R_{t}+R_{1}\right)$, the input voltage of ADS1115 is AIN0 $=V_{0}$. Therefore, the calculated temperature output $\mathrm{AD}$ value is $\mathrm{CODE}=2^{\mathrm{N}} \times \mathrm{R}_{\mathrm{t}} \times\left(\frac{\mathrm{AIN}}{\mathrm{V}_{\text {ref }}}\right)$, the obtained $\mathrm{AD}$ values are transmitted to the microcontroller for processing. After calibration, the accuracy of temperature measurement can reach $0.1^{\circ} \mathrm{C}$.

\subsection{BDM910 module Introduction}

Drifting buoy is an important function of positioning and communicating[6]. This paper selects BDStar Navigation Company launch a dual module BDM910 which support the function of RDSS/RNSS. The module integrates high performance RDSS RF transceiver chip, $10 \mathrm{~W}$ output power amplifier module, Beidou dedicated RDSS baseband circuit, and a domestic BD2 B1/GPS L1 miniaturization navigation and positioning module, it can achieve RDSS positioning, communication function, RNSS navigation and positioning function, Positioning accuracy of 5 meters, communication 
success rate of more than $95 \%$. The input and output data interface is the USART port, 3.3V TTL level, greatly facilitate the communication between the microcontroller and the module.

\subsection{Power management module}

The power supply is made up of 3 sets of parallel connection of large capacity Lithium battery, which are connected in series in 4 sections. In order to keep the low power consumption in the working state and the sleep state, the system adopts the method that the main chip and the peripheral module distinguish the power supply, that is, the main chip uses ultra-low quiescent current DCDC regulator chip, the power supply module uses Beidouopt coupler MOS tube voltage DCDC chip control output with ENABLE function, and the other peripheral circuits are controlled by low loss MOS tube. The design of this kind of structure can ensure that only the main chip consumes a small amount of power after the system is in a dormant state. In fact, when the system enters low power consumption station, the standby current of the entire system is only $20 \mathrm{uA}$, the standby power consumption for a year is only $0.17 \mathrm{AH}$.

\section{4 the design of software system}

The working states of the system are divided into dormant state, waiting state and working state. In order to try to achieve low power consumption, In most of the time, the system is in a dormant state, the main chip is in standby mode but only kernel clock RTC is working and the rest of the peripherals including the Beidou module is in power down mode. When the RTC alarm clock wakes up STM32, the state of the magnetic switch is detected first, if the state is switched on, the magnetic switch is closed, the system immediately enters the waiting state, the peripheral devices in addition to the magnetic switch is still in power down state, the main chip detects the state of the magnetic switch every 3 second, if the magnetic switch is still guided by the general rules continue to enter the waiting state, otherwise, it is switched off and the system enters the working state. The first time the system will control the buzzer to sound 1 second. In working state, all peripherals are powered up, the main chip detects the voltage of the battery, collects the temperature data and positioning data, Sends the data to the base station through the Beidou communication module, and if the successful feedback is sent, the system will enter the sleeping state. According to the conversion between system states, part of the flow chart of system software is shown in Figure 4. 


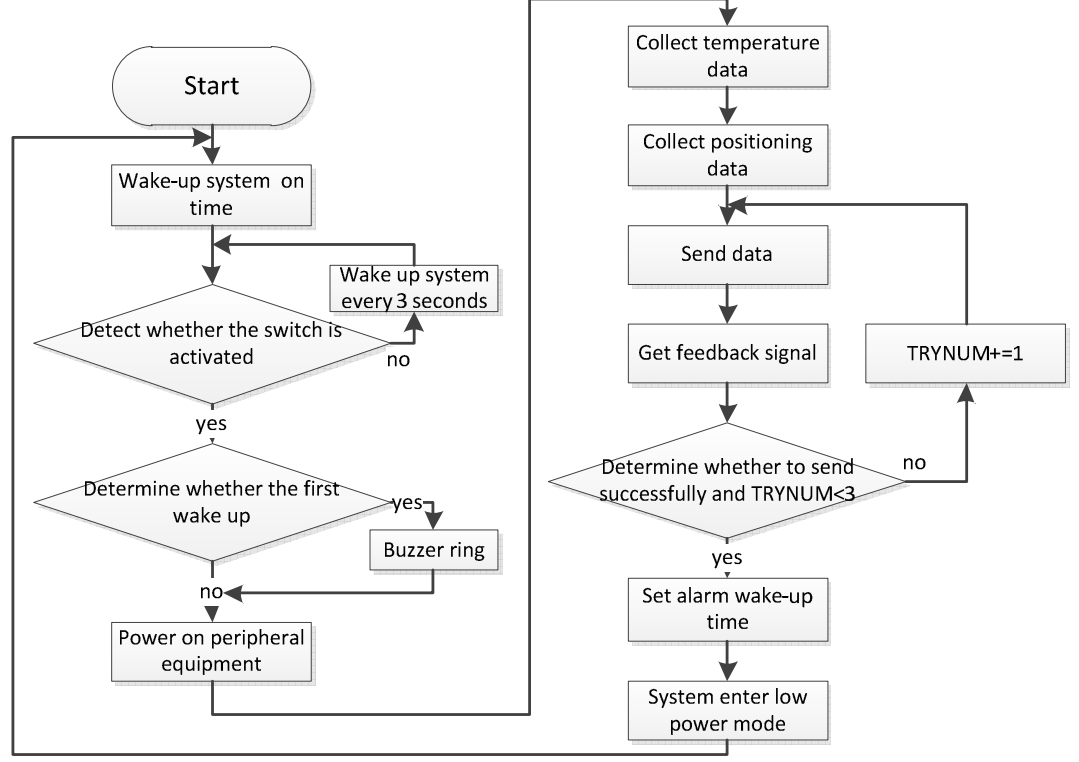

Fig. 4. System software flow chart

\section{Experimental result}

20 sets of drifting buoy designed by Institute of Oceanology, Chinese Academy of Sciences were invested in the East China Sea with the scientific survey ship "KeXue" in June 1,2016. Each buoy in every whole point to the shore receiving system transmits the current position information, the parsed data receiving software based display and stored in the txt file and the MATLAB software can analyze the moving trajectory and the motion state of each drifting buoy. The following are the diagram for receiving software and part of the analysis of data .

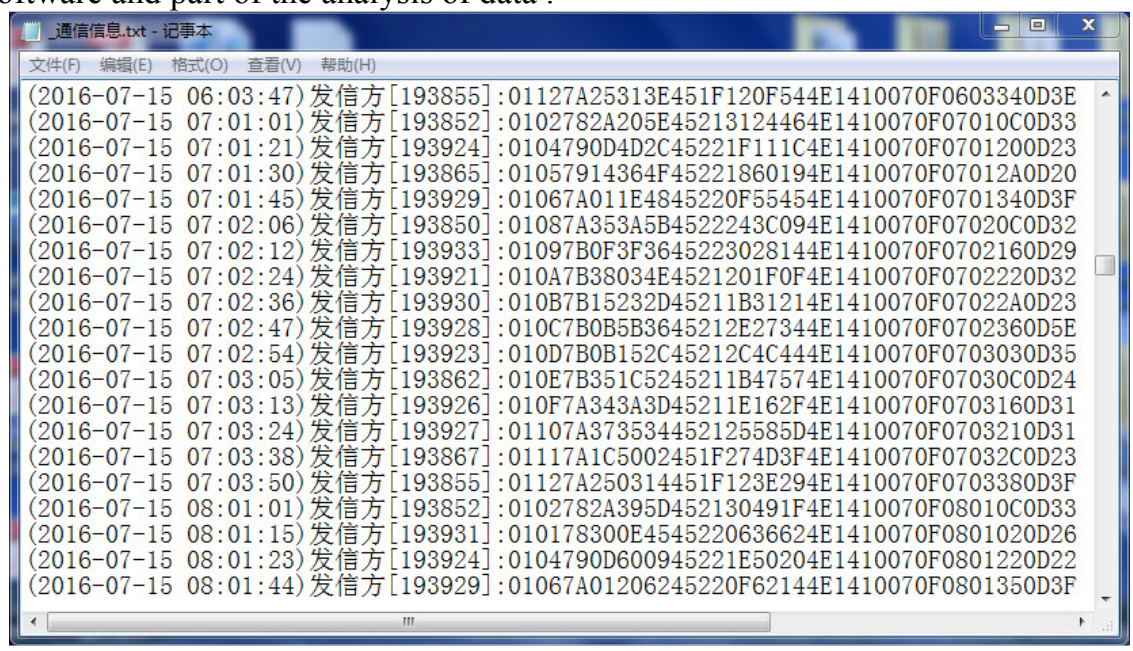

Fig. 5. Shore receiving data

Table 2 drifting buoy data (2016/07/15)

\begin{tabular}{|c|c|c|c|c|c|c|}
\hline Date & Time & No. & Longitude & Latitude & Tem. & Battery voltage \\
\hline $2016 / 07 / 15$ & $07: 01: 01$ & 02 & $120^{\circ} 42.0828^{\prime} \mathrm{E}$ & $33^{\circ} 49.9286{ }^{\circ} \mathrm{N}$ & 25.3 & 14.51 \\
\hline $2016 / 07 / 15$ & $07: 01: 21$ & 04 & $121^{\circ} 13.1975^{\prime} \mathrm{E}$ & $34^{\circ} 29.4380^{\prime} \mathrm{N}$ & 24.9 & 14.35 \\
\hline $2016 / 07 / 15$ & $07: 01: 30$ & 05 & $121^{\circ} 20.1390^{\prime} \mathrm{E}$ & $34^{\circ} 24.2460{ }^{\circ} \mathrm{N}$ & 25.2 & 14.32 \\
\hline $2016 / 07 / 15$ & $07: 01: 45$ & 06 & $122^{\circ} 01.0775^{\prime} \mathrm{E}$ & $34^{\circ} 15.2182{ }^{\prime} \mathrm{N}$ & 25.4 & 14.63 \\
\hline $2016 / 07 / 15$ & $07: 02: 06$ & 08 & $122^{\circ} 53.1493^{\prime} \mathrm{E}$ & $34^{\circ} 36.1536^{\prime} \mathrm{N}$ & 24.8 & 14.50 \\
\hline $2016 / 07 / 15$ & $07: 02: 12$ & 09 & $123^{\circ} 15.1618^{\prime} \mathrm{E}$ & $34^{\circ} 48.1026^{\prime} \mathrm{N}$ & 25.1 & 14.41 \\
\hline
\end{tabular}




\begin{tabular}{|l|l|l|l|l|l|l|}
\hline $2016 / 07 / 15$ & $07: 02: 24$ & 10 & $123^{\circ} 56.0084^{\prime} \mathrm{E}$ & $33^{\circ} 32.7951^{\prime} \mathrm{N}$ & 25.2 & 14.50 \\
\hline $2016 / 07 / 15$ & $07: 02: 36$ & 11 & $123^{\circ} 21.0900^{\prime} \mathrm{E}$ & $33^{\circ} 27.1257^{\prime} \mathrm{N}$ & 24.8 & 14.35 \\
\hline $2016 / 07 / 15$ & $07: 02: 47$ & 12 & $123^{\circ} 11.2335^{\prime} \mathrm{E}$ & $33^{\circ} 46.1003^{\prime} \mathrm{N}$ & 24.7 & 14.94 \\
\hline $2016 / 07 / 15$ & $07: 02: 54$ & 13 & $123^{\circ} 11.0542^{\prime} \mathrm{E}$ & $33^{\circ} 44.1952^{\prime} \mathrm{N}$ & 24.3 & 14.53 \\
\hline $2016 / 07 / 15$ & $07: 03: 05$ & 14 & $123^{\circ} 53.0725^{\prime} \mathrm{E}$ & $33^{\circ} 27.1826^{\prime} \mathrm{N}$ & 25.1 & 14.36 \\
\hline $2016 / 07 / 15$ & $07: 03: 13$ & 15 & $122^{\circ} 52.1490^{\prime} \mathrm{E}$ & $33^{\circ} 30.56799^{\prime} \mathrm{N}$ & 24.7 & 14.49 \\
\hline $2016 / 07 / 15$ & $07: 03: 24$ & 16 & $122^{\circ} 55.1362^{\prime} \mathrm{E}$ & $33^{\circ} 37.2262^{\prime} \mathrm{N}$ & 24.9 & 14.49 \\
\hline $2016 / 07 / 15$ & $07: 03: 38$ & 17 & $122^{\circ} 28.2048^{\prime} \mathrm{E}$ & $29^{\circ} 39.1977 ' \mathrm{~N}$ & 25.3 & 14.35 \\
\hline $2016 / 07 / 15$ & $07: 03: 50$ & 18 & $122^{\circ} 37.0078^{\prime} \mathrm{E}$ & $29^{\circ} 18.1591 ' \mathrm{~N}$ & 25.4 & 14.63 \\
\hline
\end{tabular}

The trajectory maps of No.14 and No.18 drifting buoy are as follows.

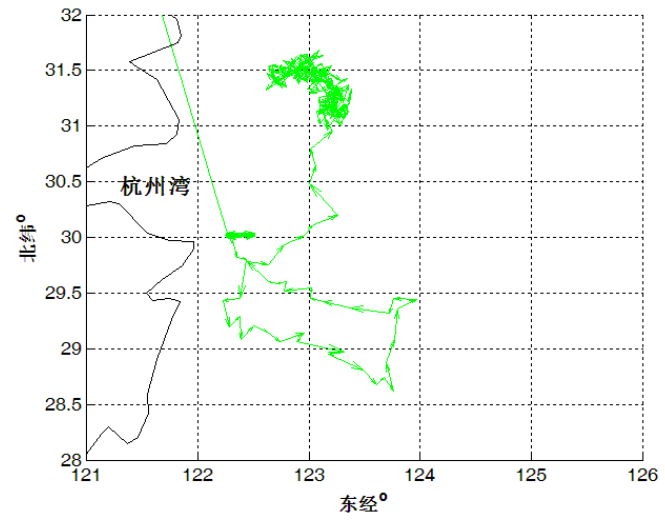

Fig. 6. No.16 drifter trajectories

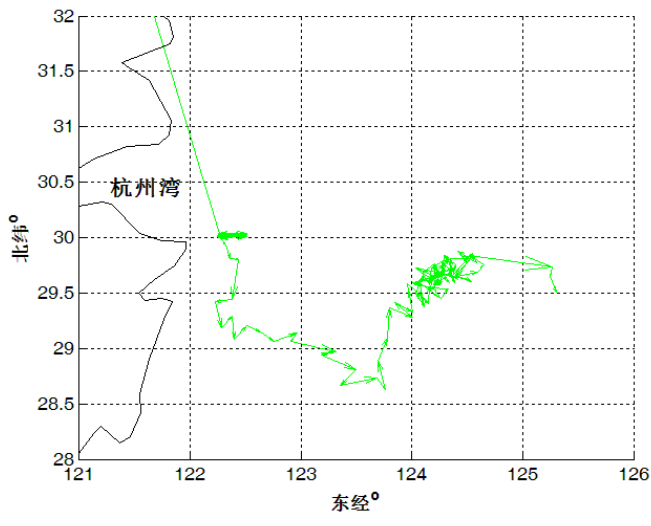

Fig. 7. No.18 drifter trajectories

\section{Conclusion}

In this paper, a surface drifting buoy system based on Beidou communication module is designed, through the Beidou satellite receiving station based on shore sending real-time data acquisition, providing the reliability support for the acquiring some real-time elements and track currents of the ocean current in some certain sea area in long time real-time access to a sea currents. It can be widely used in marine science research.

Acknowledgments. The project was financially supported by Key research and development of science and technology Program (Grant No. 2016YFC1402602), by major scientific research equipment R \& D projects of Chinese Academy of Sciences (Grant No. YZ201522 and No. YZ201625).

\section{References}

[1] Lizhong Yu,Guanglin Shan, Development and experimental study of surface drifting buoy[J].Ocean technology,1997,(02):3-13.

[2]XIN kai,ZHANG Xi-yan, QI Sheng-bo,CHEN Song-xi, STM32 based design of marine environmental data acquisition system[J].Shandong science,2014,(02):8-12.

[3]Dang Chao-qun, ZHANG Suo-ping, QI Zhang-hui, LI Ming-bing,SUN Dong-bo. Research on data transmission of deep and remote sea GPS wave buoy based on BeiDousatellitessystem[J]. Transducer and Microsystem Technologies.2016[1]:46-48.

[4]PENG Wei, XU Jun-chen, DU Yu-jie etc. Design of Marine Monitoring Data Transmitting System Based on Beidou Satellites System[J].Ocean Technology,2009,28[3]:13-15.

[5] Miguel Martinez Ledesma. Development of an oceanographic drifter with IRDIUM bidirectional communication capability[D]. Palma (JllesBalears): University of Balearic Islands, 2012:1-51.

[6]LIU Ke-feng, JIANG Guo-rong, CHEN Yi-de etc. Analysis of upper-ocean surface currents of the South China Sea derived from satellite-tracked drifter data[J]. Journal of Tropical Oceanography.2014,33[5]:13-21. 